\title{
DESENVOLVIMENTO E SUSTENTABILIDADE NA AMÉRICA LATINA: VELHA HISTÓRIA, NOVOS CAMINHOS
}

\begin{abstract}
RESUMO
O desenvolvimento, considerado durante muito tempo um valor universalmente aceito, e meta de toda sociedade moderna, hoje é questionado, inclusive sobre a forma como é produzido. É demonstrada a importância do desenvolvimento sustentável em direção à conquista de melhores condições de vida. Determinou-se como objetivo principal deste estudo apresentar insights para a maximização da sustentabilidade enquanto dinamizadora da trajetória de desenvolvimento na América Latina. Foram considerados o Painel Intergovernamental sobre Mudanças Climáticas, a Organização das Nações Unidas, o Protocolo de Quioto, entre outros estudos de validade e aceitabilidade internacional para propor parâmetros estratégicos aos negócios da AL.
\end{abstract}

Palavras-chave: Desenvolvimento; Sustentabilidade; América Latina.

\section{DEVELOPMENT AND SUSTAINABILITY IN LATIN AMERICA: OLD STORY, NEW DIRECTIONS}

\begin{abstract}
The development, considered long been a universally accepted value and goal of every modern society, is now questioned, including on how it is produced. It is shown the importance of sustainable development towards the achievement of better living conditions. It was determined as the primary objective of this study to provide insights for maximizing sustainability as a stimulus to development trajectory in Latin America. The Intergovernmental Panel on Climate Change, the United Nations, the Kyoto Protocol, among other studies with international validity and acceptability were considered for propose strategic business parameters to the AL.
\end{abstract}

Keywords: Development; Sustainability; Latin America. 
DESARROLLO Y SOSTENIBILIDAD EN AMÉRICA LATINA: HISTORIA ANTIGUA, NUEVOS RUMBOS

\section{RESUMEN}

El desarrollo, considerado durante mucho tiempo un valor universalmente aceptado y la meta de toda sociedad moderna, ahora se cuestiona, en particular sobre la forma en que se produce. Se muestra la importancia del desarrollo sostenible para el logro de mejores condiciones de vida. Se determinó que el objetivo principal de este estúdio és proporcionar una visión para maximizar la sostenibilidad como un estímulo a la trayectoria de desarrollo en América Latina. El Grupo Intergubernamental de Expertos sobre el Cambio Climático, de las Naciones Unidas, el Protocolo de Kyoto, entre otros estudios de validez y aceptabilidad internacional se consideraron para proponer parámetros estratégicos a los negócios de la AL.

Palabras-clave: Desarrollo; Sostenibilidad; América Latina.

\footnotetext{
${ }^{1}$ Doutorando em Administração pela Universidade Federal de Santa Catarina - UFSC. Professor Visitante da Faculdade Mater Dei. Brasil. E-mail: taysosilva@ hotmail.com

${ }^{2}$ Doutor em Engenharia de Produção pela Universidade Federal de Santa Catarina - UFSC. Professor do Departamento de Ciências da Administração da Universidade Federal de Santa Catarina - UFSC. Brasil. E-mail: mfpcris@gmail.com

${ }^{3}$ Doutor em Engenharia de Produção pela Universidade Federal de Santa Catarina - UFSC. Professor do Departamento de Ciências da Administração da Universidade Federal de Santa Catarina - UFSC. Brasil. E-mail: marinocad@gmail.com
} 


\section{INTRODUÇÃO}

A Organização das Nações Unidas tem encorajado ações regionais coordenadas para a promoção do desenvolvimento sustentável e a América Latina - AL é uma das regiões que requerem importantes esforços neste sentido. A comunidade internacional interessa-se por tais esforços e pelos resultados já alcançados, mas clama por ações em todos os níveis para o desenvolvimento com vistas ao futuro $(\mathrm{RIO}+20)$.

Com relação ao desenvolvimento, considerado durante muito tempo um valor universalmente aceito, e meta de toda sociedade moderna, hoje ele é questionado, inclusive sobre a forma como é produzido, tendo tanto fatores materiais ou imateriais como determinantes de sua produção, além de não se ter uma resposta precisa sobre suas consequências serem realmente positivas. $\mathrm{O}$ desenvolvimento passou a ser depreciado ao ponto de tornar-se uma busca desenfreada do crescimento econômico, ameaçando seriamente os próprios fundamentos das sociedades no planeta (JEAN, 2010). Quando é produzido com base em exploração inter-classes ou apoiado na exaustão de recursos naturais, exemplifica-se os questionamentos voltados à avaliação de seus desdobramentos positivos em um cômputo geral. Pode ser, em casos como estes, mera alocação de recursos. Em outras palavras, desenvolve-se um aspecto em detrimento de outro e, na somatória, pode haver resultado nulo ou, até mesmo, negativo, tendo em conta os custos envolvidos nesta alocação.

A história recente do desenvolvimento da $\mathrm{AL}$, comentada no terceiro item, corrobora com estas considerações. Portanto, explicita-se a necessidade, conforme Jean (2010), da percepção da importância do desenvolvimento sustentável capaz de modificar a identidade do desenvolvimento tido como o progresso da humanidade em direção à conquista de melhores condições de vida, com a expansão da democracia e com o pleno desenvolvimento das culturas. Assim, determinou-se como objetivo principal deste estudo apresentar insights para a maximização da sustentabilidade enquanto dinamizadora da trajetória de desenvolvimento na AL.

A transição para uma sociedade mais responsável e consciente é emergencial dado o consumo desmedido e práticas predatórias degeneradoras dos recursos não renováveis (ROSSATO; LOZANO; BELLEN, 2010). O presente estudo, ao importar discussões de especialistas sobre sustentabilidade para a perspectiva econômica demonstra a diferenciação das oportunidades para o desenvolvimento da América Latina, apoiando-se na transição para uma sociedade mais responsável. Cabe destacar grupos de oportunidades elencadas pela Comissão Econômica para América Latina e Caribe CEPAL, para análise e cumprimento dos propósitos deste estudo, por três motivos essenciais: a) A CEPAL é a principal fonte de informações sobre economia e sociedade da AL (BIELCHOWSKY, 2000); b) Tais oportunidades podem transcender o simples aumento dos ganhos econômicos, ocasionando mudanças estruturais permanentes contributivas para o benefício humano; c) A exploração destas podem ter seus impactos sociais e ambientais mitigados ou, praticamente, anulados e, em muitos casos, mais do que poderiam em outras regiões do planeta, como será demonstrado na presente análise.

\section{CONSIDERAÇÕES SOBRE DESENVOLVIMENTO}

De maneira sucinta, importa ao início das considerações sobre o tema, tratar da concepção do desenvolvimento. Há uma classificação sequencial amplamente aceita, distribuída em cinco etapas sucessivas, interconectadas por uma determinada lógica. Cabe ressalvar que as características das etapas apresentadas, logo na sequência, não se constituem grupos estanques, enquadrando-se perfeitamente às condições das sociedades pertinentes às respectivas etapas. Disparidades em âmbitos do desenvolvimento são frequentes. A Coreia do Sul é um importante exemplo. De acordo com o World Bank (2013), 99\% de sua população chega, ao menos, no ensino secundário. Entretanto, Silva, Pereira e Cário (2013) observam que não obstante as políticas incisivas voltadas para a ciência e educação resultem em um desempenho excepcional no empreendedorismo e inovação da Coréia do Sul, não há resultados uniformes nos diversos âmbitos, especialmente no que diz respeito à disparidade de gênero, pois, enquanto em outros países emergentes, conforme o GEM (2013), o número de homens e mulheres que empreendem praticamente é o mesmo, naquele país elas participam apenas com $17,5 \%$ do total.

Ressalvadas exceções, o desenvolvimento das sociedades pode sequenciar-se, então, por meio das cinco etapas. $1^{\text {a }}$ ) A Sociedade Tradicional - tem funções limitadas com características pré-newtonianas, suscetível à manutenção sistemática. Poderia surgir a manufatura ou ter aumento na produtividade, contudo, apenas até determinado limite, levando à necessidade de canalizar seus recursos à agricultura, atribuindo, assim, poder ao proprietário de terras; $2^{\mathrm{a}}$ ) As précondicionadas para o Arranco - quando o avanço científico começa a ser aplicado à produção, visto primeiramente na Grã-Bretanha. O progresso econômico passa a ser uma finalidade, direcionando a educação, despontando instituições financeiras e, esparsamente, a moderna empresa industrial; $3^{\mathrm{a}}$ ) $\mathrm{O}$ Arranco - há a superação das resistências ao desenvolvimento, aprimoramento das lideranças políticas, elevação das taxas de poupança, investimento e, nas indústrias, reinvestimento aprimorando e otimizando os recursos naturais e métodos de 
produção, o que ocorre também com o setor agrícola; $4^{\text {a }) ~ A ~ M a r c h a ~ p a r a ~ a ~ M a t u r i d a d e ~-~ e x p a n d e-s e ~ a ~}$ tecnologia à toda atividade econômica e um investimento maior na produção a faz superar o incremento demográfico. Após um amadurecimento, nesta etapa, a indústria e tecnologia sofisticam-se; $5^{\mathrm{a}}$ ) A Era do Consumo em Massa - a população é alijada do acesso aos itens da necessidade básica unicamente, o consumo em massa fortalece a produção de bens duráveis, de consumo e os serviços. O acesso democrático à mais sofisticada tecnologia humana faz a sociedade buscar novos anseios traduzidos em bemestar social (ROSTOW, 1966).

Por serem de amplo conhecimento no meio científico as condições econômicas essenciais da AL, sem o intuito de promover uma tendência para o argumento aqui, pode-se afirmar, previamente às exposições do próximo item, que as sociedades lantinoamericanas enquadram-se, em sua maioria, mais com a primeira metade das etapas do desenvolvimento, como foram expostas, do que com a segunda metade. Como citado anteriormente, descompassos são inevitáveis neste processo e devem ser considerados para caracterizar estas nações mais nas primeiras etapas do desenvolvimento, tendo em conta que, conforme Rostow (1966), por exemplo, a partir da sociedade tradicional observa-se o desenvolvimento geralmente estimulado pelas potências estrangeiras, somadas a forças de modernização interna. O nível do avanço e emprego das tecnologias e inovações é um aspecto claro para o crescimento nas etapas de desenvolvimento, deixando ela de ser o objetivo supremo apenas na última das etapas.

\section{CONSIDERAÇÕES SOBRE DESENVOLVIMENTO RECENTE NA AL}

Após a Segunda Guerra, as questões econômicas na América Latina tiveram a teoria do comércio internacional como base para análise de seus problemas econômicos. A velha ordem econômica considerava necessário o retrocesso da periferia. Os países da AL deveriam exportar produtos primários, conforme suas aptidões sem industrializar-se. A ideologia de livre-comércio existente, baseada em vantagens comparativas da especialização da produção, servia para garantir a exploração nas trocas internacionais beneficiando os países industrializados. Tal situação se mantinha porque os ganhos de produtividade nos países centrais não refletiam em diminuição dos preços dos produtos exportados aos países subdesenvolvidos (CARDOSO, 1993).

Mesmo sendo esta uma realidade distante à época, a industrialização, na concepção teórica Celso Furtado (apud ALMEIDA, 2009), é a grande mola propulsora da produtividade dos fatores $\mathrm{e}$ da dinamização da acumulação do capital e, assim, indispensável para o desenvolvimento. Historicamente, a industrialização, assim como a incorporação de novas combinações tecnológicas, exerce papel fundamental na transformação das estruturas desiguais da economia brasileira e na ruptura do subdesenvolvimento.

Países subdesenvolvidos não ficaram restritos à exportação de alimentos como condição "sine qua non" à sua inserção na economia capitalista mundial. Simultaneamente, suas importâncias refletem-se enquanto provedores de matéria-prima à crescente industrialização. $\mathrm{O}$ surgimento da grande indústria nos países centrais aumenta a classe trabalhadora e também eleva sua produtividade. Desta forma, explica-se a demanda por matérias-primas advindas dos países subdesenvolvidos. Mas a importância da América Latina neste contexto transcende a simples condição de exportadores primários para influenciar nas alterações da economia industrial mundial quando a acumulação pautada na mais-valia absoluta passe a depender mais da produtividade do trabalho (TRASPADINI; STEDILE, 2011). Na América Latina, a CEPAL considerava, por outro lado, a necessidade da industrialização com o apoio do capital estrangeiro, reforma fiscal, fundiária e, sobretudo, a ação do estado para conduzir o desenvolvimento nacional. A periferia buscava desenvolver-se por meio da urbanização, da tecnificação da produção agrário-mineradora e da industrialização da economia (CARDOSO, 1993) para que chegassem ao mesmo patamar dos países industriais clássicos (CARDOSO, 1993; TRASPADINI; STEDILE, 2011).

Entretanto, a industrialização incipiente, substitutiva de importações, ainda não seria suficiente para proporcionar acumulação de recursos na periferia, mas simplesmente significava uma migração de determinado processo produtivo para outra região. $\mathrm{Na}$ visão furtadiana, esta descentralização não necessariamente acarretaria em industrialização no sentido autônomo da produção. O que ocorre, na verdade, é deslocar no todo ou em parte a produção física em uma estrutura dependente na qual o produto continua sendo concebido no centro dominante (ALMEIDA, 2009) e, com os desdobramentos, a industrialização na América Latina se dá de forma paulatina. Apresentando início tímido, teve oportunidades de crescimento justamente quando fatores externos dificultavam o acesso dos mais abastados a produtos importados. A lucratividade dos capitalistas dependentes, da qual decorria sua estruturação, advinha das crises quando aumentava a oferta de mão-de-obra, reduzindo o custo da mesma e em função do protecionismo e baixa concorrência que permitiam a elevação dos preços venais. Tal fato, permite que a indústria absorva grandes contingentes de trabalhadores que trabalhem em uma jornada estendida e intensificada, acelerando a acumulação de capital no setor industrial (TRASPADINI; STEDILE, 2011), constituindo mais um fator contributivo à desigualdade entre classes. 
$\mathrm{Na}$ América Latina e Caribe a acentuada desigualdade tem raízes históricas e coloniais, persistindo em regimes republicanos. Esta desigualdade remonta a uma negação de direitos sistemática com base em questões raciais e de propriedade, relegando grande contingente à escravidão, subjugação e expropriação. Com a reprodução de privilégios a determinadas classes em detrimento de outras, manteve-se as assimetrias nas condições de vida e de direitos, perpetuando, por meio de um padrão de desenvolvimento, as disparidades socioeconômicas. Recorrentes lutas sociais se ampliaram afirmando a busca de direitos de grupos sociais excluídos tradicionalmente (CEPAL, 2010). Há por aqui uma economia baseada na superexploração do trabalhador. A produção industrial é independente das condições salariais porque não é um elemento essencial à subsistência do operário e porque, da forma descrita, a oferta de mercadorias cresce em detrimento da redução do poder de compra dos operários. Para, então, generalizar o consumo de manufaturas, acarretam as necessidades de ampliação do consumo das camadas médias e do aumento da produtividade, o que barateia a mercadoria (TRASPADINI; STEDILE, 2011).

Quando uma economia periférica industrializa-se, principalmente substituindo importações, o mercado interno passa a ser o grande consumidor da oferta. Tal expansão se faz de fundamental importância para a circulação de mercadorias e para a continuidade de todo o processo produtivo na economia (CARDOSO, 1993). Pelo menos na Argentina, Brasil e México, conjunturas de poder beneficiaram determinadas classes permitindo a acumulação que financiou os investimentos internos e a ampliação relativa do consumo em centros urbanos, concomitantemente com a remuneração dos setores exportadores acentuada pela Segunda Guerra (CARDOSO; FALETTO, 1975), além da expansão do consumo por parte da classe trabalhadora e da nova classe média. Entretanto, melhorias no mercado não refletem diretamente melhorias na qualidade de vida da população. Certos segmentos ganham, mas nada garante que o piso da sociedade obtenha melhoria. Assim, há necessidade de rever os padrões de dependência, mais especificamente as formas de exploração entre classes e de dominação pública (CARDOSO, 1993).

Neste sentido, cabe ressaltar que ao aumentar a produtividade, o trabalhador não consegue o maisvalor. O capitalista individual, assim, consegue diminuir o valor de sua mercadoria em relação aos custos totais de produção, obtendo uma mais-valia superior à de seus concorrentes. Esta mais-valia extraordinária atribui mais lucros a determinados capitalistas sem modificar o grau de exploração do trabalhador. $\mathrm{Na}$ economia latino-americana, o baixo nível de desenvolvimento das forças produtivas condiz com a exploração do trabalhador pelos mecanismos de intensificação do trabalho, pela prolongação da jornada de trabalho e pela expropriação de parte do trabalho do proletário (TRASPADINI; STEDILE, 2011).

Esta superexploração do trabalho é uma das formas pela qual o capitalismo dependente se firma. A outra forma é com a penetração do capital financeiro e industrial que impulsiona o desenvolvimento das economias subdesenvolvidas (ALMEIDA, 2009). Havia um movimento de busca de capitais industriais estrangeiros, caracterizando a década de 1950 pelo fluxo de capitais do centro para a periferia quando as corporações industriais passaram a atuar como investidoras, podendo o investimento ser canalizado para empréstimos à infraestrutura, aproveitar um mercado existente ou assegurar o controle de um mercado em expansão (CARDOSO; FALETTO, 1975).

Marini (apud TRASPADINI; STEDILE, 2011) considera que a partir da segunda metade do século XX, os avanços na concentração de capital em escala mundial centralizaram um enorme montante de divisas financeiras nas grandes corporações imperialistas que empregam estes recursos no exterior, culminando em um fluxo de capital para as indústrias da periferia. Anteriormente, enquanto durou a desorganização da economia mundial durante o período de guerras, desenvolveram-se as bases industriais periféricas que ofereciam taxas atrativas de lucro em função da superexploração do trabalho. Além disso, a evolução na produção de bens de capitais fez com que a periferia se transformasse em um mercado consumidor para parte desses produtos, sobretudo os obsoletos, configurando a industrialização da América Latina em uma nova divisão internacional do trabalho.

Convém explicitar duas formas iniciais de dependência de países da AL para com o exterior. No primeiro caso, o próprio processo de independência resultou da ação de grupos agro-exportadores os quais quando do rompimento político com Espanha ou Portugal mantiveram o controle do sistema produtivo nacional, reorganizando as relações do comércio internacional, especialmente com foco na Inglaterra, então centro hegemônico do poder capitalista. No segundo caso, o período de expansão econômica voltado ao mercado externo se realizou por meio do investimento externo (CARDOSO, 1971).

Tem-se agora, um novo modelo de dependência. Além do sistema de importaçõesexportações de produtos, há também as relações de investimentos industriais implementadas pelos países centrais nos novos mercados. Em adição, a industrialização na América Latina fora favorecida pelo seu mercado interno. $\mathrm{O}$ que pesa em contrário no tipo de industrialização, baseado em captação de recursos no exterior, é justamente o elevado grau de endividamento, caracterizando, mais uma vez a relação de dependência (CARDOSO; FALETTO, 1975), principalmente para fazer frente às dificuldades dos capitais nacionais, à escassez de poupança e à frouxidão do empresariado (ALMEIDA, 2009).

O governo federal interveio acelerando o processo de acumulação de capital no país, 
principalmente a partir de 1950, desenvolvendo políticas econômicas voltadas para o setor industrial concernentes tanto à infraestrutura quanto ao crédito financeiro (ALMEIDA, 2009). Neste sentido, na medida em que vão se investindo recursos na industrialização da periferia, esta vai se libertando de uma forma de dependência e ingressa em outra, desta vez financeira. Este mecanismo de reprodução da dependência se relaciona ao endividamento externo crescente quando das necessidades de importação de tecnologia produzida nas economias centrais (CARDOSO, 1993).

A industrialização, no entendimento furtadiano, é a base na qual o desenvolvimento deve ser assentado, assim como na acumulação de capital endogenamente e na incorporação de técnicas racionais em consideração à economia de mercado. Para tanto, seria necessária a intervenção estatal de forma planejada, na regulação e orientação dos investimentos. Também faz-se importante a colaboração dos países centrais em financiar o acesso à tecnologia de ponta (ALMEIDA, 2009).

A política de investimentos de capital estrangeiro proporcionou sérios conflitos entre distintas forças sociais. Tratando-se dos interesses do setor popular urbano ou camponês, diminui-se a capacidade de acumulação de riquezas nas mãos de capitalistas, desestruturando as ligações políticas entre o setor latifundiário e o estado populista. Caso o estado optasse por transferir rendas do setor agrário para o urbano, haveria também a rejeição do setor agrário quando o mercado internacional apresentar um cenário desfavorável. Por outro lado, o próprio setor urbanoindustrial necessita de um maior contingente de pessoas para seu desenvolvimento. Se o setor industrial dominasse esta disputa pelo poder estatal, precisaria para instaurar a industrialização de determinadas conjunturas políticas, manter os preços externos, enfrentar-se com o setor agro-exportador, conter a política salarial, intensificar a exclusão dos populares urbanos no processo econômico, fechar o mercado interno e manter a exclusão agrária e o crescimento das disparidades regionais (CARDOSO; FALETTO, 1975).

Havia um consenso em que as transformações ocorridas na economia brasileira a partir da década de 50 decorriam de investimentos estrangeiros amplamente favorecidos pelo estado. Somando-se este fato à alegação acima, é inegável a influência do capital externo na transformação econômica brasileira (ALMEIDA, 2009). O amplo espectro dos níveis de desenvolvimento das forças produtivas no mercado global apresenta significativas diferenças em suas composições orgânicas de capital e, consequentemente, em distintas formas de exploração da classe trabalhadora. As economias industriais inflam a demanda de produtos primários. Como efeito, intensifica-se a exploração da mão-de-obra, baixando sua composição orgânica e aumentando o valor das mercadorias produzidas, a mais-valia e o lucro. Tal situação estimula as exportações de capital para a periferia em busca dos lucros mais vantajosos, fazendo com que a apropriação da mais-valia pelos países centrais configure uma taxa média de lucro internacional. Nos países dependentes, por outro lado, a baixa taxa de lucros decorrente da elevação de sua composição orgânica é recompensada pelos processos de superexploração da mão-de-obra entre outras características favoráveis à alta rentabilidade do capital variável nas economias agrárias (TRASPADINI; STEDILE, 2011).

A CEPAL é a principal fonte de informações sobre a economia e sociedade latino-americana. Seu princípio é a imprescindível necessidade de intervenção estatal para o desenvolvimento econômico desta periferia, sendo assim, visa influenciar a sua coalizão dominante política. Seu enfoque histórico-estruturalista produz um conhecimento baseado no comportamento dos agentes sociais e na trajetória das instituições, pelo método indutivo que, conjuntamente com a produção de Prebisch, transparece a magnitude de sua contribuição. Assim, o desenvolvimento da América Latina não o é da mesma forma como ocorreu com os países Centrais. Os primeiros 50 anos da CEPAL podem ser categorizados em cinco fases: $1^{\text {a }}$ ) Anos 1950 - foco na industrialização, sobretudo substitutiva; $2^{\mathrm{a}}$ ) Anos 1960 - reformas para desobstruir a industrialização; $3^{\text {a }}$ ) Anos 1970 - reorientação dos estilos de desenvolvimento na direção da industrialização pró-exportadora e da homogeneização social; 4a) Anos 1980 - superação do endividamento externo, renegociando a dívida para ajustar o crescimento; 5 ) Anos 1990 - transformação produtiva com equidade, por meio de políticas públicas (BIELCHOWSKY, 2000).

Muitas das ideias cepalinas, já existentes previamente, foram sistematizadas cientificamente no sentido de legitimar os argumentos da CEPAL, sendo reconhecidos pela academia nacional e internacional. A representação política já entendia, ao final do século XIX, a crise no balanço de pagamentos e escassez de divisas como decorrente das trocas desiguais ocasionadas pelas vias do livre-comércio, o que também fora avalizado por Jorge Street em 1933. Em 1928, Washington Luís defendeu o protecionismo alfandegário e pensadores autoritários dos anos 30 defendiam a imprescindibilidade da intervenção estatal na resolução do marasmo social decorrente do interesse da elite agrária, com forte influência política, na manutenção do modelo corrente. Getúlio Vargas, antes de 1948, posicionou-se a favor de incentivos estatais à industrialização, começou a utilizar a expressão "desenvolvimento econômico", atribuindo ao estado a responsabilidade pelo fomento financeiro voltado à alavancagem da produção. Considerou a crise de 1929 decorrente da superprodução descompromissada com a expansão dos mercados em um descompasso catastrófico, desmistificou a ideia da especialização 
primária do país ser uma vocação definitiva, chamando atenção para a constante desvalorização dos produtos primários perante os industrializados. Também no discurso do Estado Novo constam os termos dependência e estrutura, frequentemente abordados pelos cepalinos. Aqui, a indústria provê ferramentas para a produção agrária e a agricultura insumos para a economia industrial (FOSECA, 2000). Os posicionamentos de GetúlioVargas ajudam a demonstrar como o Brasil historicamente é uma das molas propulsoras do desenvolvimento econômico na região, seja em potencialidade econômica ou em posicionamento estratégico.

$\mathrm{Na}$ primeira fase da CEPAL, em pleno processo de industrialização impulsionado pelo pósguerra, Prebisch, a maior personalidade desta comissão à época (CARDOSO, 1993b), com o apoio de outros especialistas sobre a realidade latino-americana desenvolveu uma teorização própria capaz de atender expectativas dos governos do continente. Os países periféricos, conforme Prebisch, sofriam as consequências econômicas da desvalorização de seus produtos primários, cuja demanda era inelástica no exterior, perante os industrializados, justificando seu argumento protecionista no sentido de substituir as importações. Somado ao desequilíbrio na balança de pagamento por tais diferenças de preço, o processo de industrialização e a base pouco diversificada da economia, tendia-se à inflação, comum nestes países, assim como o desemprego são fatores considerados na construção dos planejamentos, encabeçados por Celso Furtado, orientados para suprir deficiências nestes governos (BIELCHOWSKY, 2000).

Durante os anos 1960, o contexto da CEPAL foi caracterizado, principalmente, por instabilidade macroeconômica, pressões inflacionárias e sociais, industrialização e Revolução Cubana, responsável pelo direcionamento sociológico dos estudos. Com a crise internacional de 1973/4, houve a preocupação com a dependência e a vulnerabilidade externa concernentes à expansão das exportações industriais e aos desdobramentos da crise de 1973/4, além do reforço das exportações e da industrialização, a qual encontraria espaço tanto no mercado interno quanto exportador. Na década de 1980, inicialmente os juros elevados levavam a um ajuste recessivo nestas economias macroeconomicamente frágeis e, concomitantemente, elas submetiam-se a outros condicionantes de credores internacionais. O contexto remetia a situações de megainflação e, quando associada à recessão causou efeitos devastadores sobre as finanças públicas. Esta crise desloca o esforço intelectual para a oposição aos choques do ajuste exigido pelos credores das dívidas, na busca por um ajuste expansivo e não recessivo. Para tanto, seriam necessários alívio das pressões dos credores, menor protecionismo dos países centrais e direcionamento da política econômica latino-americana para exportações (BIELCHOWSKY, 2000).
$\mathrm{Na}$ última fase deste período, houve ligeira recuperação econômica, estabilização de preços, controle do déficit fiscal, cautela nos empréstimos e reformas que incluíam a abertura comercial e financeira, privatizações e flexibilização das leis trabalhistas. Por outro lado, valorização cambial e pressões de credores também caracterizaram países do bloco. A CEPAL lança como prioridade a "Transformação produtiva com equidade", assentando a estratégia na conquista da competitividade internacional "autêntica" baseada no avanço tecnológico de processos produtivos, com ênfase na qualificação da força de trabalho. Além disso, a "TPE" foi base para muitos documentos de estudos cepalinos, transparecendo sua influência nos desdobramentos econômicos latino-americanos (BIELCHOWSKY, 2000).

Conforme Rodriguez (2009), para os neoestruturalistas da CEPAL os elevados recursos externos existentes em fase concomitante à alta da demanda agregada e da atividade, faz com que credores e investimentos exógenos reajam negativamente comprometendo a sustentabilidade macroeconômica destes países. Esse movimento tendencia a economia desses países a retrocederem às zonas de vulnerabilidade.

Durante os trinta primeiros anos da CEPAL, a América Latina experimentou, concomitantemente com o resto do mundo, profundas transformações e um rápido desenvolvimento industrial e acelerado processo de urbanização, encabeçado pelo Brasil, que obteve um crescimento médio de 8,5\% ao ano, e pelo México com $7,5 \%$ de crescimento anual. Neste período, os países do bloco latino-americano tiveram um crescimento industrial entre $6 \%$ e $7 \%$, enquanto a Europa Ocidental obteve 5,2\% em média. Entretanto, enquanto a Europa partiu de uma situação de destruição da guerra, a América Latina saiu de um baixo nível de industrialização e um alto nível de crescimento populacional. Esta situação fora acompanhada por modificações em setores específicos da indústria manufatureira, de forma similar ao que ocorrera em países desenvolvidos (PAIVA, 2006).

\section{DESENVOLVIMENTO TERRITORIAL SUSTENTÁVEL}

Neste item, será apresentada uma nova perspectiva para o modelo de desenvolvimento passível de ser implementado ou, em um importante grau, espelhado para a América Latina. Conforme Jean (2010), a noção de desenvolvimento territorial inclui mais do que apenas outra forma de tornar inteligíveis as características do desenvolvimento regional e local em diferentes escalas. É uma mudança paradigmática nos estudos sobre desenvolvimento regional. Assim, as ciências sociais ao assumirem uma perspectiva inter e transdisciplinar adquirem novos instrumentos visando reconhecer a importância do território como uma 
construção social e não apenas como uma realidade biofísica tangível. O processo de construção social dos territórios é mais pertinente à história e à sociologia, enquanto as dinâmicas econômicas delimitadas espacialmente interessam mais às ciências econômicas e as realidades ambientais de tais territórios estão relacionadas especialmente à geografia e às ciências naturais enquanto delimitação de estudos.

Em 1980 a Organização Internacional para a Conservação do Ambiente patrocinou um amplo estudo acerca da conservação dos recursos naturais, visando um desenvolvimento sustentável. A extraordinária expansão da conscientização sobre o desenvolvimento sustentável levou à realização da Eco-92, no Rio de Janeiro e, no mesmo ano, a Organização Mundial do Turismo levantou a bandeira do Turismo Sustentável, conduzindo à publicação do Guia de Desenvolvimento Turístico Sustentável, em 1993 (SERVA, 1999). Tais preocupações são reflexo e refletem as necessidades da redução da emissão de poluentes, especialmente, segundo o Protocolo de Quioto (1998) e o IBGE (2012), aqueles causadores do efeito estufa.

Em um contexto marcado pela busca da redemocratização da sociedade brasileira e pelo desgaste progressivo do modelo de modernização conservadora adotado, o conceito de sustentabilidade das estratégias de desenvolvimento em um primeiro momento parecia sugerir a efetivação do direito dos cidadãos ao emprego, ao exercício de cidadania plena e a um meio ambiente salutar. Entretanto, mesmo com os avanços no aperfeiçoamento de instrumentos de regulação jurídica e econômica, conjuntamente à conscientização progressiva da opinião pública, o sistema de gestão socioambiental continuou caracterizado pela escassez de recursos financeiros imprescindíveis à implementação das medidas planejadas e por sérias deficiências na capacidade técnico-científica em todos os níveis de ação governamental além do descrédito junto à população (VIEIRA, 2007).

Especificamente, no caso do Brasil, atualmente há necessidade de maior atenção às contradições, aos paradoxos e aos impasses que cercam o projeto de criação e implementação da agenda 21 . Deve-se avaliar de forma mais clara e realística o que tem sido feito ultimamente para que o projeto entre efetivamente em prática. Faz-se, então, necessária a criação de um projeto nacional estratégico ao invés de permanecer na administração de projetos setoriais, divididos e fortemente impregnados de um tendenciamento tecnocrático. Seria interessante $o$ fortalecimento dos instrumentos de coordenação institucional com uma visão sistêmica em longo prazo (VIEIRA, 2007).

Em se tratando de desenvolvimento territorial, as contribuições de Bernard Pecqueur, de Bruno Jean e de Ricardo Abramovay demonstram que o mesmo representa tanto um novo discurso acadêmico capaz de superar os enfoques no âmbito do desenvolvimento local e regional quanto um novo discurso social especificando novas realidades socioeconômicas, principalmente novas relações entre economia e território. Para eles, há a necessidade de considerar as dimensões econômicas, sociais e ambientais, incluindo a superação das fronteiras disciplinares. A abordagem do desenvolvimento territorial questiona a percepção de espaço fordista, favorecendo uma visão multiescalar e multidimensional (LÉVESQUE, 2010).

O território constitui um desafio no sentido da questão regional manifestar a demanda de satisfação de interesses exclusivamente pessoais e, também, uma busca coletiva de desenvolvimento ligado a um dado território cujas identidades e fronteiras estão delineadas. Este é também um desafio político quando diferentes territórios com uma mesma identidade sociopolítica buscam um desenvolvimento pensado em termos de aproveitamento de seus potenciais, desde que não incremente as disparidades regionais. $\mathrm{O}$ território, então, passa a ser produto do desenvolvimento, em função deste só ter sentido caso proporcione um ambiente de vida sustentável, além da satisfação das necessidades individuais. Aqui é intrínseca a promoção de um desenvolvimento territorial correspondente às demandas sociais de desenvolvimento (JEAN, 2010).

Jean (2010) propõe uma reconfiguração do desenvolvimento territorial, como fora proposto por Phillippe Aydalot, apresentando a noção de "desenvolvimento territorial solidário", no qual está implícita a noção de sustentabilidade. Para o autor, as noções de território e de desenvolvimento territorial têm se propagado nos discursos sociais e científicos, provavelmente, por evocarem o fato do desenvolvimento territorial ser considerado uma construção social. A nomeação do território é condição sine qua non para sua existência, constituindo um dos primeiros sinais de uma construção social, colocando os atores sociais em uma ação dinâmica em um espaço determinado de ocupação. Tal identificação, proporcionada pela nomenclatura do território, constitui importante referencial na formação das identidades individual e social, servindo como um pilar estruturante das mesmas. Tal marca territorial historicamente é influenciada por uma certa leitura das características biofísicas além do voluntarismo das coletividades humanas e daquilo que se caracteriza como um projeto de território específico. Assim, os territórios são "entidades socioespaciais, ou relacionadas às atividades humanas conduzidas num dado espaço; eles refletem, portanto, um procedimento de construção política" (JEAN, 2010, p.51). Assim, a nomenclatura "América Latina", enquanto bloco de países similares não apenas por sua origem idiomática, especialmente ibérica, mas por sua base socioeconômica delineadora do território específico, refletem um procedimento de construção política comum nestes países, como é aqui aceito. 
Com relação às políticas públicas de desenvolvimento, passa-se de uma política de desenvolvimento regional, voltada a um nivelamento das condições de desenvolvimento, para uma política de apoio a iniciativas de coletividades regionais e locais que clamam por uma pluralidade de atores sociais. Assim, emerge a questão da governança local visando definir as orientações estratégicas compartilhadas. Esta governança local possibilita reunir atores políticos, econômicos e os representantes da sociedade civil para elaborarem diagnósticos compartilhados e de projetos comunitários (LÉVESQUE, 2010). Neste contexto, o desenvolvimento sustentável faz-se importante no estabelecimento de um novo modelo, capaz de promover a coexistência entre fatores econômicos, sociais e ambientais, transcendendo o modelo economicista, reducionista e unidimensional (ROSSATO; LOZANO; BELLEN, 2010).

Uma maior igualdade em matéria de direitos, oportunidades e bem-estar proporciona condições para um país enfrentar os desafios no mundo cada vez mais complexo e competitivo visto que uma competitividade baseada em capacidades humanas providas de oportunidades de educação e acesso ao emprego formal remetem a avanços de produtividade sustentável a longo prazo. A ampliação da igualdade influencia positivamente $\mathrm{o}$ fortalecimento da representação política dos grupos secularmente excluídos conferindo a estes maior participação em decisões quanto à redistribuição de recursos e ampliação de serviços públicos. A redução na distância discrepante de poder entre grupos sociais não será automática dado o caráter histórico das relações de poder, patrimônio, reconhecimento e redes de relações em nossas sociedades. As desigualdades como as de gênero, idade, etnia devem ser consideradas sob pena de uma cidadania genérica ser fonte reprodutora destas discrepâncias arraigadas. Assim, promover uma cidadania igualitária exige um esforço em mudanças institucionais importantes (CEPAL, 2010).

Este desafio de reduzir as desigualdades existentes decorre historicamente para os formuladores de políticas públicas nos países da América Latina e Caribe. As questões institucionais do mercado de trabalho são fundamentais para comportar os aumentos de produtividade proporcionados por um novo paradigma tecnológico, refletindo em redução de jornadas de trabalho, aumentos salariais e acesso à proteção social. A elevação salarial também pode ser estimulada por meio de políticas públicas que direcionem investimentos estatais na oferta de serviços públicos necessários à reprodução da força de trabalho além de ocasionar importante efeito estabilizador nos ciclos econômicos (CEPAL, 2010).

\section{OPORTUNIDADES ELENCADAS PELA CEPAL PARA A AL}

Primeiramente, o processo de substituição de importações como fora dado na AL durante o processo de industrialização (BIELCHOWSKY, 2000; CARDOSO 1993; CEPAL 2008) proporcionou um setor manufatureiro capaz de conferir competitividade neste âmbito à região. A industrialização voltada ao mercado interno permitiu a criação de um aparato industrial e capacidades tecnológicas mínimas para produzir manufaturas em diferentes setores, cujos processos de aprendizagem conduziram a capacidades e estruturas empresariais fundamentais para absorver o impacto da liberalização do comércio exterior e reorientar para a competitividade internacional. Nas últimas quatro décadas é notório o aumento da participação das exportações no faturamento das indústrias manufatureiras nos países maiores e mais industrializados (Argentina, Brasil e México), tendência esta acompanhada pela maioria dos países da AL (CEPAL 2008).

Em segundo lugar, há um espaço de competitividade claramente definido em setores com uso intensivo de recursos naturais. Tais setores apresentam oportunidades de diversificação exigida pela segmentação cada vez maior dos mercados. Neste âmbito destaca-se o complexo agroalimentar da AL por muitas razões. Sua valiosa contribuição na oferta de alimentos e segurança alimentar e como fonte de energia alternativa. Muitos outros países utilizaram os recursos naturais para promover diversificação produtiva e a competitividade (CEPAL 2008).

O terceiro grupo de oportunidades emerge da mineração metálica, a qual vem contribuindo para a inserção de vários países no mercado externo. Expectativas favoráveis no contexto internacional, sobretudo em função da demanda de países asiáticos permitem prever a expansão dos investimentos nesta área. Além disto, filiais de empresas transnacionais constituem joint ventures com empresas locais, o que ocasiona transferência de conhecimentos. Para atender às necessidades de qualificação dos recursos humanos, implementam-se iniciativas de capacitação frequentemente mediante a criação de centros de formação e firmação de convênios com universidades. Assim, também há estímulos para a formulação de estratégias públicas para desenvolver a capacidade de recursos humanos (CEPAL 2008). Desta forma, a mineração contribui também para um desenvolvimento humano no sentido de trazer maior conhecimento e investimento na educação do cidadão.

Esta sequência de oportunidades para a AL listadas pela CEPAL (2008) finaliza-se com o setor de serviços em distintos âmbitos como transportes, finanças e turismo. O setor terciário apresenta uma crescente porcentagem no PIB e na oferta de emprego nas economias desenvolvidas e na AL. Argentina, Brasil, Costa Rica, Honduras e Paraguai registraram as taxas mais altas de crescimento nesta categoria. 
Destacam-se o crescimento maior de serviços de transporte em Chile, Guatemala, Paraguai e El Salvador além dos serviços de turismo no Brasil, Cuba e Guatemala, com taxas superiores a $20 \%$ anuais nas últimas décadas.

\section{ANÁLISES DOS REFERENCIAIS SOBRE DESENVOLVIMENTO E SUSTENTABILIDADE PARA A AL}

A questão da desigualdade na AL mostra-se arraigada, inclusive por suas bases históricas, cuja minimização parece ainda estar caminhando a passos lentos, pois já é uma preocupação latente desde os anos 1960 (BIELCHOWSKY, 2000). Há necessidade do Estado, a partir de um olhar crítico das bases históricas, perfilar uma postura correta voltada a um equilíbrio entre o mercado e o cidadão. $\mathrm{O}$ mercado não produz automaticamente a igualdade entre os cidadãos, destacando a necessidade do Estado em tal tarefa. A macroeconomia desempenha papel importante nos padrões de trabalho, exigindo adoção de políticas públicas direcionadas a um padrão de inserção internacional, favorecendo a integração interna. Também deve-se estabelecer políticas públicas voltadas ao acesso à tecnologia, informação e ao crédito por parte das PMEs com vistas à diminuição da desigualdade de condições produtivas e competitivas desta categoria geradora de empregos (CEPAL, 2010). Políticas de renda mínima, educação e saúde colocam a população pobre em condições de contribuir para com o desenvolvimento econômico, podendo garantir-lhes desenvolvimento pessoal e trabalho (BRESSERPEREIRA, 2004).

A sustentabilidade econômica de uma região também perpassa pelas condições endógenas de suficiência de recursos. Com um PIB superior a 2,2 trilhões de dólares, o Brasil lidera a economia da AL enquanto sua maior potência, praticamente duas vezes superior ao segundo país mais rico, o México (WORLD BANK, 2014), mantendo as principais relações comerciais internas do bloco. Tal fato tem ajudado os demais países a atravessarem a recente crise internacional com a ajuda da estabilidade de demanda interna brasileira, pois, como foi apontado por Cardoso (1993), em economias periféricas que se industrializaram, o mercado interno passa a ser o grande consumidor da oferta. Também, não é de hoje que o Brasil desponta-se como locomotiva da AL. Como fora exposto por Paiva (2006), de 1950 a 1980 enquanto Estados Unidos crescia à taxa de 3,6\% ao ano, a Europa à 5,2 \%, os países da $\mathrm{AL}$ variavam entre 6 e $7 \%$ a. a., sendo o Brasil o carro-chefe a uma taxa de $8,5 \%$. Também, conforme a CEPAL (2008), os três mais industrializados e maiores países, Brasil, México e Argentina têm apresentado aumento nas exportações de manufaturas, acompanhado pela maioria dos países do bloco.
Entretanto, ainda é necessário valorizar a distribuição dos frutos da ampliação da demanda para as mais diversas camadas da sociedade, tanto quanto possível. Uma vez estabelecidas particularidades do território da AL, possibilita-se, conforme Lévesque (2010), considerar os recursos e os fatores de produção baseados nas coletividades, os fatores não materiais e extra-econômicos além de recursos específicos e dificilmente transferíveis como as formas de cooperação, a coesão social, as habilidades sociais, as capacidades de adaptação e inovação, a qualidade de vida e os serviços. Tudo isso considerando-se as questões institucionais. Neste sentido, as colocações de Fajnzylber (apud PAIVA, 2006) destacam a possibilidade de conciliar o crescimento e equidade simultaneamente, diferentemente de outras interpretações então existentes que pressupunham o desenvolvimento ser facilitado pela concentração de renda. Para este autor a distribuição equitativa dos ganhos advindos dos avanços na produção conferiria sustentabilidade para continuação do desenvolvimento econômico. Crescimento, competitividade e equidade são indissociáveis em um processo de ciclo virtuoso no qual um sistema industrial coexiste com elevação no consumo interno e maiores níveis de investimento.

A linha divisória cronológica apresentada neste artigo são documentos oferecidos por meio de estudos aprofundados das necessidades de sustentabilidade das atividades econômicas organizados pelo Painel Intergovernamental sobre Mudanças Climáticas, pela Organização das Nações Unidas, entre outros estudos de validade e aceitabilidade internacional. Com base nisto, ao avaliar as propostas da CEPAL para o direcionamento de esforços em um sentido de desenvolvimento da AL, há de se considerar, entretanto, as condições pelas quais se explorarão tais oportunidades e pelas quais haverá a continuidade da ação humana nesta região. Em consenso indiscutível, são necessários esforços para a redução das emissões de gases de efeito estufa, as quais estão envolvidas na maioria das atividades econômicas.

Para cumprimento do objetivo deste estudo, considera-se o entendimento proposto pela Organização das Nações Unidas que para haver o desenvolvimento sustentável, é necessário atender às necessidades do presente sem comprometer a capacidade das gerações futuras atenderem à suas próprias necessidades (SERVA, 1999). A ONU reconhece a necessidade de vários avanços no sentido de implementar resultados para o desenvolvimento de forma sustentável, entre eles a erradicação da pobreza, o crescimento econômico e a diversificação de atividades (RIO+20, 2012), como a melhor exploração dos serviços de turismo que, conforme a CEPAL (2008), vem apresentando taxas superiores a $20 \%$ ao ano nas últimas décadas em países da AL.

Existe a preocupação mundial com a redução da emissão de gases do efeito estufa (POTOCOLO DE QUIOTO, 1998; IBGE, 2012). Se tal assertiva é 
verdadeira, a sustentabilidade também pode ser estimulada ao se considerar lucros advindos de atividades econômicas que reduzam as emissões de gases nocivos à atmosfera. O Protocolo de Quioto (1998), por meio de um mecanismo de desenvolvimento limpo, demonstra esforços neste sentido ao estabelecer benefícios às partes que colocarem em prática projetos que resultem em reduções certificadas de emissões, cumprindo seus compromissos quantificados de limitação e redução das emissões. O comércio das emissões recompensa e estimula o desenvolvimento voltado à sustentabilidade.

Tais preocupações têm sido foco de interesse internacional dada a magnitude das consequências decorrentes das emissões. Há fortes sinais de que as atividades humanas estão aumentando rapidamente a concentração de alguns dos gases de efeito estufa, elevando rapidamente a temperatura da terra. As consequências já são amplamente perceptíveis como a intensificação de secas, furacões, inundações, subida do nível do mar e difusão de doenças, inevitavelmente levando a sérios prejuízos materiais e humanos (IBGE, 2012). Acusa-se, desta forma, a insustentabilidade da atividade humana da forma como tem sido dada e, ao mesmo tempo, chama-se novamente atenção à importância da preocupação com a redução das emissões no caminho de um desenvolvimento sustentável, indicando a valorização pelo mercado mundial de mercadorias produzidas sob a égide da sustentabilidade.

A energia é um aspecto chave da produção no sentido de um desenvolvimento sustentável (IBGE, 2012), o que a envolve na essência de praticamente a totalidade das oportunidades elencadas pela CEPAL em item anterior. Nos dados confirmados pelo IBGE (2013), o Brasil enquanto maior potência econômica da América Latina (WORLD BANK, 2014; IBGE, 2013), exemplifica aos demais países do bloco como é possível contribuir para esta redução. Conforme descrito pelo IBGE (2012), com uma matriz energética com forte participação de geração hidráulica e, em menor escala, de biomassa, o setor de produção de energia no Brasil contribui pouco para as emissões de gases de efeito estufa. Diferentemente do que ocorre com o resto do mundo, especialmente em países mais industrializados como este.

\section{PRINCIPAIS CONTRIBUIÇÕES CONSIDERAÇÕES FINAIS}

Os registros e estudos históricos demonstraram o modelo de desenvolvimento implementado na América Latina, em sua história recente. Houve esforços para a construção de uma indústria local capaz de promover a substituição de importações, gerar empregos e crescimento econômico. Em fato, avanços foram alcançados em determinados âmbitos. Entretanto, o modelo incentivador da atividade econômica também seria baseado na exploração dos trabalhadores, cultuando a desigualdade histórica vinda desde o colonialismo. Somente nos anos 1990 iniciou-se um debate sobre o crescimento econômico com equidade.

A equidade representa aspecto chave do desenvolvimento sustentável na AL, especialmente porque a região é constituída basicamente por países emergentes, cuja tendência é que, no médio e longo prazo, continue apresentando aumento no consumo interno, considerando, inclusive, a classificação das etapas de desenvolvimento apresentada no segundo item deste artigo, na qual a quinta e última etapa é caracterizada pelo consumo em massa, fortalecendo a demanda por bens duráveis, de consumo e por serviços. Nenhum destes países atingiu esta etapa de maturação, indicando, mais uma vez possibilidades de um amplo aumento do consumo interno, especialmente influenciado pela equidade na distribuição dos frutos do desenvolvimento econômico. Este aumento não se traduz em sustentabilidade, no sentido de buscar autossuficiência. Entende-se aqui que as trocas entre as economias podem sim serem benéficas, mas a sustentabilidade de um território baseia-se, também, em sua dinâmica produtiva endógena como uma forma soberana de crescimento, protecionista às relações internacionais que impõem dependências intrínsecas as quais têm explorado historicamente a região.

A eficiência energética e a utilização de energias renováveis contribuem para o desenvolvimento sustentável. Em países menos desenvolvidos a substituição de fontes de energia pode contribuir para a redução da mortalidade atenuando a poluição do ar, reduzindo o consumo insustentável de lenha e consequente desmatamento (IPCC, 2008), devendo a proposta para o desenvolvimento condizer com as características do país, de seu povo e lideranças, caso contrário dificilmente será implantada e executada (WOLFE, 1976). Obviamente, uma economia verde voltada para o desenvolvimento sustentável deve respeitar a soberania nacional perante os recursos naturais (RIO+20, 2012), corroborando para a exploração de energia oriunda, por exemplo, de usinas hidrelétricas conforme o potencial de pluviosidade característico da região tropical do continente em seu território Latino Americano, como fora demonstrado pelo caso do Brasil, enquanto carrochefe do bloco.

A Organização das Nações Unidas reconhece a necessidade de mudanças fundamentais nos modos de produção e consumo das sociedades para atingir as metas globais de desenvolvimento sustentável. Os países têm reafirmado compromissos em diminuir os subsídios para a exploração de combustíveis fósseis que podem contribuir para o desperdício em consumo e para minar o desenvolvimento sustentável (RIO+20, 2012). Desta forma, demonstra-se uma tendência à conscientização de mercados consumidores internacionais em privilegiar produtos advindos de territórios que produzam utilizando energia de fontes renováveis, colocando alguns países da $\mathrm{AL}$, como o 
Brasil, que possuem uma matriz energética predominantemente baseada em fontes renováveis numa posição de vantagem no comércio globalizado. Assim, a proposta de um desenvolvimento pautado na sustentabilidade passa a ser estratégico para a região, com vistas especialmente à manutenção do crescimento de maneira a não comprometer a capacidade produtiva para as gerações vindouras.

Uma estratégia nacional valorativa da melhor utilização dos recursos naturais, inclusive em uma perspectiva malthusiana, mostra-se promissora no sentido de esperar uma ampla valorização da exportação de alimentos, observando-se o aumento da demanda por alimentos ocasionado pela ampliação da população mundial, acompanhada pelo descompasso com a produção de alimentos. A melhor utilização dos recursos naturais também abrange o turismo. A importante expansão deste tipo de serviço exposta neste estudo constitui não apenas mais uma possibilidade de desenvolvimento sustentável, mas também capaz de contribuir para a divulgação e conscientização de mercados externos quanto à sustentabilidade de nosso meio de produção, pautado, entre outros fatores, em uma ampla matriz energética renovável, como exemplificada pela maior potência do bloco.

Enquanto contribuição efetiva deste estudo, dois aspectos principais são observados. Primeiramente, estabelece-se uma correlação entre dois eixos teóricos. Enquanto um traz a discussão sob a perspectiva econômica desenvolvimentista na América Latina, o outro resgata a noção de desenvolvimento territorial sustentável, sendo analisados como dialogáveis, contendo intersecções e complementações, destacando-se nesta dualidade, a importância do desenvolvimento equitativo. Em segundo, por meio desta intersecção das correntes científicas, foi permitida uma análise quanto à racionalização dos recursos naturais e políticas de distribuição de renda serem imperativos para a AL em função de suas potencialidades e deficiências. A potencialidade da expansão do consumo interno e a valorização exógena de recursos naturais, especialmente quando tratados de forma sustentável, podem constituir um novo caminho para uma velha história.

O aprofundamento deste estudo poderá tratar de outras oportunidades exploráveis pela América Latina, aproveitando seu potencial nato, mais sustentáveis do que as atualmente exploradas. Ainda para estudos futuros, há a necessidade de investigar e apresentar outros critérios de sustentabilidade implementáveis conjuntamente tanto com as oportunidades citadas pela CEPAL quanto às atividades já em andamento, visando justamente a sustentabilidade do desenvolvimento como é tratado neste artigo.

\section{REFERÊNCIAS}

Almeida, J. E. (2009). Subdesenvolvimento e dependência: uma análise comparada de Celso Furtado e Fernando Henrique Cardoso. Tese de Doutorado. Porto Alegre. Universidade Federal do Rio Grande do Sul. Faculdade de Ciências Econômicas. Programa de Pós-Graduação em Economia.

Bielchowsky, R. (2000). Cinquenta anos de pensamento na CEPAL: uma resenha. Rio de Janeiro: Record.

Bresser-Pereira, L. C. (out/dez. 2004). Proposta de Desenvolvimento para o Brasil. Revista de Economia Política. 24(4).

Cardoso, F. H. (1993). As ideias e seu lugar: ensaios sobre as teorias do desenvolvimento. Petrópolis: Vozes.

\& Faletto, E. (1975). Dependência e desenvolvimento na América Latina: ensaio de interpretação sociológica. Rio de Janeiro: Zahar.

. (1993b). Originalidade da cópia: CEPAL e a ideia de desenvolvimento. Petrópolis: Vozes.

(1971). Política e desenvolvimento em sociedades dependentes. Rio de Janeiro: Zahar.

CEPAL. (2010). A hora da igualdade: brechas por fechar, caminhos por abrir. Brasília: Nações Unidas.

(2008). La transformación productiva 20 años después: viejos problemas, nuevas oportunidades. Santo Domingo: Naciones Unidas.

GEM. (2013). Global Entrepreneurship Monitor. Recuperado em: 03 abr. 2013, de: <www.gemconsortium.org>.

Fonseca, P. C. D. (jul/set. 2000). As origens e as vertentes formadoras do pensamento cepalino. Revista Brasileira de Economia. 54(3).

IBGE. (2012). Indicadores de Desenvolvimento Sustentável: Brasil 2012. Rio de Janeiro: IBGE.

(2013). Países@. Recuperado em: 02 fev. 2013, de: <http://www.ibge.gov.br/paisesat/>.

IPCC. (2008). Câmbio climático 2007: informe de sínteses. Ginebra: IPCC.

Jean, Bruno. (2010). Do desenvolvimento regional ao desenvolvimento territorial sustentável: rumo a um 
desenvolvimento territorial solidário para um bom desenvolvimento dos territórios rurais. In: VIEIRA, Paulo F. et al. (Org.). Desenvolvimento territorial sustentável no Brasil. Florianópolis: Aped; Secco.

Lévesque, B. (2010). Comentários: As bases teóricas e metodológicas do enfoque de desenvolvimento territorial sustentável: Convergências e aportes específicos. In: VIEIRA, Paulo F. et al. (Org.). Desenvolvimento territorial sustentável no Brasil. Florianópolis: Aped; Secco.

Paiva, Suzana. C. F. (2006). Estratégias de política industrial e desenvolvimento econômico: ideias e ideais de Fernando Fajnzylber para a América Latina. Tese de Doutorado: Universidade Estadual de Campinas.

Protocolo de Quioto. (1998). A convenção sobre mudança do clima. Brasília: C\&T.

RIO+20. (2012). United Nations Conference on Sustainable Development. Rio de Janeiro: United Nations.

Rossato, J., Lozano, M. S. P. L. \& Bellen, H. M. (2010). Atores sociais nas dinâmicas de desenvolvimento territorial sustentável : O caso da ASSHORTI. In: Encontro Nacional da Associação Nacional dos Programas de Pós-Graduação em Administração, 34, Rio de Janeiro, Anais. Rio de Janeiro.
ROSTOW, W. (1966). Etapas do desenvolvimento econômico. Rio de Janeiro: Zahar.

Serva, M. (1999). A dimensão sócio-organizacional do desenvolvimento sustentável. (CD Rom). Anais do I EBANGRAD - I Encontro dos Cursos de Graduação em Administração, Salvador.

Silva, T., Pereira, M. F. \& Cário, S. A. F. (2013). Considerações sobre inovação e atividade empreendedora na trajetória sul coreana. Revista de Administração e Inovação. 10(4), 9-33.

Traspadini, R. \& Stedile, J. P. (2011). Ruy Mauro Marini: vida e obra. São Paulo: Expressão Popular.

Vieira, P. F. (2007). Ecodesenvolvimento: do conceito à ação. In : SACHS, Ignacy. Rumo à ecossocioeconomia: teoria e prática do desenvolvimento. São Paulo: Cortez.

Wolfe, M. (1976). Desenvolvimento: para que e para quem? Rio de Janeiro: Paz e Terra.

WORLD BANK. GDP (current US\$). (2014). Recuperado em 10 fev. 2014, de: <http://data. worldbank.org/indicator/NY.GDP.MKTP.CD>.

(2013). World development indicators.

Recuperado em 19 jun. 2013, de: <www.worldbank.org>. 